Type D Personality and illness perceptions in myocardial infarction patients

Running Head: Type D Personality and Illness Perceptions

Lynn Williams PhD ${ }^{1 *}$, Rory C. O’Connor $\mathrm{PhD}^{2}$, Neil R. Grubb M.D ${ }^{3}$ and Ronan E. O’Carroll $\mathrm{PhD}^{2}$.

${ }^{1}$ School of Social Sciences, University of the West of Scotland, UK

${ }^{2}$ Department of Psychology, University of Stirling, Stirling, UK

${ }^{3}$ Edinburgh Royal Infirmary, Edinburgh, UK

*Correspondence to:

Lynn Williams

School of Social Sciences

University of the West of Scotland

Paisley

PA1 2BE

Tel:+44(0) 1418483956

email: 1ynn.williams@uws.ac.uk 


\section{Type D personality and illness perceptions in post - myocardial infarction patients}

\section{Abstract}

Objectives: To determine the relationship between Type D personality (the tendency to experience negative emotions and to be socially inhibited) and illness beliefs in post-myocardial infarction (MI) patients. Methods: One hundred and ninety two MI patients participated. Patients were assessed on demographic variables and completed the Type D Scale (DS14) and Brief illness perceptions questionnaire (BIPQ) one week post-MI. Results: MANOVA revealed that Type D patients were significantly different from non-Type D patients on every illness perception dimension. Type D patients believe that their illness has significantly more serious consequences $(p<.001)$, will last significantly longer $(p<.001)$, will be significantly less controllable by them $(\mathrm{p}<.05)$ or through treatment $(\mathrm{p}<.001)$ compared to non-Type D patients, and experience significantly more symptoms that they attribute to their illness $(\mathrm{p}<.001)$. In addition, they are significantly more concerned about their illness $(\mathrm{p}<.05)$, experience significantly more emotions as a result $(\mathrm{p}<.001)$, and find their illness to be significantly less comprehensible compared to non-Type D individuals $(p<.001)$. Conclusion: Type D individuals possess a distinct profile of illness beliefs, which may help explain the adverse effect of Type D on health outcomes following MI. Future research should evaluate intervention strategies to tackle illness perceptions in these high-risk patients.

Keywords: Illness Perceptions; Myocardial Infarction; Type D Personality 


\section{Introduction}

Type D personality has been identified as an independent predictor of morbidity and mortality in cardiac patients [1-3]. Type D personality refers to the conjoint effects of the two stable personality traits negative affectivity and social inhibition [4]. Type D represents a three-fold mortality risk for cardiac patients, independent of left ventricular ejection fraction, mood states, and despite medical treatment $[2,3,5,6]$. Type $\mathrm{D}$ has also been associated with poor quality of life [6], increased psychological distress [8], and impaired health status in cardiac patients [9]. Behavioural mechanisms which may explain the negative effect of Type D on clinical outcome include engaging in an unhealthy lifestyle [10], sub-optimal consultation behaviour with medical staff $[11,12]$, and poor adherence to medication [13].

A further mechanism which may explain the link between Type D and poor cardiac prognosis is via patients' beliefs or perceptions about their illness. Evidence supporting the commonsense self-regulation model has shown that patients develop beliefs about the identity, time course, possible causes, consequences and the controllability of their illness. These beliefs are thought to determine behavioural and emotional self-regulation following a health threat $[14,15]$. Possessing beliefs that involve expectations of severe consequences and long duration of illness have been found to be related to lower quality of life [16-18], disability [19], later return to work $[16,17]$, poor attendance at cardiac rehabilitation [20], and poorer performance on a 6-minute walking task one-year after cardiac valve replacement [21].

The Type D construct has been criticised as not providing an obvious route for therapeutic intervention [24]. However, studies have clearly demonstrated that it is possible to modify patients' illness perceptions, and subsequently improve their functional outcome after MI $[22,23]$. For example, MI patients who received a brief 
in-hospital illness perception intervention had a faster rate of return to work, higher intentions to attend cardiac rehabilitation, and greater increases in exercising [23]. Therefore, given the key role of illness perceptions in predicting outcome in MI patients, and the potential to modify these perceptions, examining their role within Type D personality may provide a potential route for intervention in these high-risk patients. Consequently, the aim of the current study is to examine the association between Type D and illness perceptions in patients, one-week post-MI (as illness perceptions assessed soon after MI have been shown to have important effects on recovery [16]).

\section{Method}

\section{Participants and Procedure}

A non-consecutive sample of 192 MI patients, who were admitted to Edinburgh Royal Infirmary, participated in the study. The mean age of the participants was 66.0 $(\mathrm{SD}=10.8)$ years (range $40-88$ years). Women comprised $28.1 \%$ of the sample $(\mathrm{n}=54)$.

With informed consent and ethics committee approval, patients were asked to complete measures of Type D personality, illness perceptions, and provided demographic information.

\section{Measures}

\section{Type D Personality}

The Type D Personality Scale (DS14) is a 14-item scale comprising of 2 subscales [4]. A 7-item subscale which measures negative affectivity (NA; e.g. 'I often feel unhappy'), and a 7-item subscale measuring social inhibition (SI; e.g. 'I often feel 
inhibited in social interactions'). Respondents rate their personality on a 5-point Likert-type scale which ranges from $0=$ false to $4=$ true (items 1 and 3 were reverse scored). The NA and SI scales can be scored as continuous variables (range 0-28) to assess these personality traits independently. Participants who score highly on both NA and SI using a cut-off point of $\geq 10$ on both scales are classified as having a Type D personality. Cronbach's $\alpha=0.88$ and 0.86 respectively for NA and SI indicating excellent internal consistency in the current sample.

\section{Illness Perceptions}

The Brief Illness Perception Questionnaire (Brief IPQ) is a 9-item scale designed to quickly assess the key cognitive and emotional representations of illness [25]. Five of the items assess cognitive illness representations: consequences (the outcomes the patient expects from the illness), timeline (how long the patient believes the illness will last), personal control (how much influence they feel they have), treatment control (how effective they think their treatment will be), and identity (the symptoms they view as being part of their illness). Two of the items assess emotional representations: concern (how worried they are about their illness) and emotions (the emotional impact of the illness. One item assesses illness comprehensibility (how well they feel they understand their illness). All of these items are rated using a 0-10 response scale.

\section{Statistical Analysis}

A MANOVA was carried out to examine differences between Type D and non-Type D individuals (using the traditional categorical method of classifying Type D [6]) in each of the illness perceptions one week post-MI. In addition, correlation analyses 
were performed in order to examine the association between the multiplicative interaction term of NAxSI and illness perceptions. This second analysis was conducted in line with recent findings that have suggested Type D may be best treated as a dimensional construct [26].

\section{Results}

Prevalence of Type D Personality

From the sample of 192 participants, 65 (18 females and 47 males) were classified as Type D (33.9\%) by using the recommended cut off point of $\geq 10$ on both NA $(\mathrm{M}=11.43 ; \mathrm{SD}=5.87)$ and $\mathrm{SI}(\mathrm{M}=10.85 ; \mathrm{SD}=5.73)$ sub-scales. This corresponds to $33.3 \%$ of females and $36.1 \%$ of males being categorised as having a Type D personality. There was no effect of gender on Type D status, $\chi^{2}(1, \mathrm{~N}=192)=0.009$, ns

The Relationship between Type D Personality and Illness Perceptions - Categorical Analysis

Treating Type D as a categorical variable, MANOVA revealed that Type D individuals differ significantly on all illness perceptions (as demonstrated in Table 1). Type D individuals believe that their illness has significantly more serious consequences, will last significantly longer, will be significantly less controllable by them or through treatment compared to non-Type D patients, and experience significantly more symptoms that they attribute to their illness. In addition, they are significantly more concerned about their illness, experience significantly more emotions as a result, and find their illness to be significantly less comprehensible compared to non-Type D individuals. There was no moderating effect of gender on any of the illness perceptions. 
Insert Table 1 about here

The Relationship between Type D Personality and Illness Perceptions - Dimensional Analysis

Correlation analyses showed that Type D (NAxSI) is significantly correlated with all illness perceptions. Type $\mathrm{D}$ is positively correlated with consequences $(r(190)=.52, p$ $<.01)$, timeline $(r(190)=.39, p<.01)$, identity $(r(190)=.51, p<.01)$, concern $(r(190)=.24, p<.01)$, comprehensibility $(r(190)=-.17, p<.05)$, and emotions $(r(190)=.52, p<.01)$. Type $\mathrm{D}$ is negatively correlated with personal control $(r(190)$ $=-.17, p<.05)$, and treatment control $(r(190)=-.40, p<.01)$.

\section{Discussion}

Type D patients differed significantly from non-Type D patients on every illness perception. Given the important role that illness perceptions play in predicting outcome in cardiac patients [16], the current findings suggest that Type D may exert some of its adverse effect on cardiac health via illness perceptions. Type D patients believe that their illness will have serious consequences, last for a long time, and that treatment will be less effective in controlling their illness. These beliefs may in turn influence the behaviour of Type D individuals (e.g. believing that a treatment will be less effective could lead to medication non-adherence [13]). These findings on illness perceptions fit with previous research that has identified a relationship between Type D and unhealthy behaviour [10], and medication non-adherence [13] suggesting that Type D patients' poor self-management behaviour may be linked to their illness perceptions. Further studies on Type D patients' illness perceptions should focus on 
the evaluation of interventions to change their illness perceptions in order to test whether this results in improved post-MI outcomes for these high risk patients.

There are several limitations to the current study. First, the main limitation is the use of a cross-sectional design. Future research should examine the relationship between Type $\mathrm{D}$ and illness perceptions over time in order to investigate if illness perceptions mediate the relationship between Type D and post-MI outcome. Second, illness perceptions were measured using the Brief IPQ and it remains to be determined if similar findings would result using the full IPQ-R. Third, the participants represented a non-consecutive sample; however, we do not believe that this had an impact in terms of selection bias, as the same inclusion criteria were applied to all potential participants. Finally, it may also be considered a limitation that we have not assessed the potential moderating effects of depression and anxiety on the relationship between Type D and illness perceptions. Given the key role that NA has in illness [27], it may not be surprising to some that Type D individuals (who are by definition high on NA) score differently on illness perceptions, compared to nonType D individuals. However, we have previously shown that the interaction of NA and SI was more predictive of poor medication adherence in MI patients than either construct alone [13].

The current study is the first to identify a strong association between Type D personality and illness perceptions. Illness perceptions therefore represent one possible mechanism to explain the link between Type D and poor outcome in cardiac patients. Future research is warranted on this topic, and should focus on evaluating the effectiveness of interventions aimed at changing these illness perceptions, in order to improve post-MI outcome. 
Acknowledgements: This study was funded by the Chief Scientist Office of the Scottish Government 


\section{References}

[1] Pedersen SS, Denollet J. Is Type D personality here to stay? Emerging evidence across cardiovascular disease patient groups. Curr Cardiol Rev 2006;6:205-213.

[2] Denollet J, Sys SU, Stroobant N, Rombouts H, Gillebert TC, Brutsaert

DL. Personality as independent predictor of long-term mortality in patients with coronary heart disease. Lancet 1996;34:417-21.

[3] Denollet J, Vaes J, Brutsaert DL. Inadequate response to treatment in coronary heart disease: Adverse effects of Type D personality and younger age on 5-year prognosis and quality of life. Circulation 2000;102:630-5.

[4] Denollet J. DS14: Standard assessment of negative affectivity, social inhibition, and Type D personality. Psychosom Med 2005;67:89-97.

[5] Denollet J, Brutsaert DL. Personality, disease severity, and the risk of long-term cardiac events in patients with decreased ejection fraction after myocardial infarction. Circulation 1998;97:167-73.

[6] Pedersen SS, Lemos PA, van Vooren PR, Liu TK, Daemen J, Erdman RA, Smits PC. Type D personality predicts death or myocardial infarction after bare metal stent or sirolimus-eluting stent implantation. J Am Coll Cardiol 2004;44:9971001.

[7] Al-Ruzzeh S, Athanasiou T, Mangoush O, Wray J, Modine T, George S, Amrani M. Predictors of poor mid-term health related quality of life after primary isolated coronary artery bypass grafting surgery. Heart 2005;91:1557-62.

[8] Schiffer AA, Pedersen SS, Widdershoven JW, Hendriks EH,Winter JB, Denollet J. The distressed (type D) personality is independently associated with impaired health status and increased depressive symptoms in chronic heart failure. $E u$ J Cardiovasc Prev Rehabil 2005;12:341-46. 
[9] Mols F, Martens EJ, Denollet J. Type D personality and depressive symptoms are independent predictors of impaired health status following acute myocardial infarction. Heart 2010;96:30-35.

[10] Williams L, O'Connor RC, Howard S, Hughes BM, Johnston DW, Hay JL, O’Connor DB, Lewis CA, Ferguson E, Sheehy N, Grealy MA, O'Carroll RE. Type D Personality Mechanisms of Effect: The Role of Health-Related Behaviour and Social Support. J Psychosom Res 2008;64:63-9.

[11] Schiffer AA, Denollet J, Widdershoven JW, Hendriks EH, Smith OR. Failure to consult for symptoms of heart failure in patients with a Type D personality. Heart 2007;93:814-18.

[12] Pelle AJ, Schiffer AA, Smith OR, Widdershoven JW, Denollet J. Inadequate consultation behaviour modulates the relationship between Type $\mathrm{D}$ personality and impaired health status in chronic heart failure. Int J Cardiol, in press.

[13] Williams L, O’Connor RC, Grubb NG, O’Carroll RE. Type D personality predicts poor medication adherence in myocardial infarction patients. Psychology and Health, in press.

[14] Leventhal H, Nerenz DR, Steele DS. Illness representations and coping with health threats. In: Baum A, Taylor SE, Singer JE, eds. Handbook of psychology and health. Hillsdale, NJ: Erlbaum, 1984:219-52.

[15] Leventhal H, Benyamin Y, Brownlee S, Diefenbach M, Leventhal E, PatrickMiller L, Robitaille C. Illness representations: Theoretical Foundations. In: Petrie KJ, Weinman J, eds. Perceptions of health and illness: Current research and applications. London: Harwood Academic, 1997:19-45. 
[16] Petrie KJ, Weinman J, Sharpe N, Buckley J. Role of patients' view of their illness in predicting return to work and functioning after myocardial infarction: longitudinal study. BMJ 1996;8:209-21.

[17] French DP, Lewin RJP, Watson N, Thompson DR. Do illness perceptions predict attendance at cardiac rehabilitation and quality of life following myocardial infarction. J Psychosom Res 2005;59:315-22.

[18] Stafford L, Berk M, Jackson HJ. Are illness perceptions about coronary artery disease predictive of depression and quality of life outcomes. J Psychosom Res 2009;66:211-20.

[19] Juergens MC, Seekatz B, Moosdorf RG, Petrie KJ, Rief W. Illness perceptions before cardiac surgery predict disability, quality of life and depression three months later. J Psychosom Res, in press.

[20] Cooper A, Lloyd G, Weinamn J, Jackson G. Why patients do not attend cardiac rehabilitation: role of intentions and illness beliefs. Heart 1999;82:234-236.

[21] Rimington H, Weinman J, Chambers JB. Predicting outcome after valve replacement. Heart 2010;96:118-23.

[22] Petrie KJ, Cameron LD, Ellis CJ, et al. Changing illness perceptions following myocardial infarction: an early intervention randomized controlled trial. Psychosom Med 2002; 64:580-6.

[23] Broadbent E, Ellis CJ, Thomas J, Gamble G, Petrie KJ. Further development of an illness perception intervention for myocardial infarction patients: a randomized controlled trial. J Psychosom Res 2009;67:17-23.

[24] Lesperance F, Frasure-Smith N. Negative emotions and coronary heart disease: getting to the heart of the matter. Lancet 1996;34: 414-415. 
[25] Broadbent E, Petrie KJ, Main J, Weinman, J. The Brief Illness Perception Questionnaire (BIPQ). J Psychosom Res 2006;6: 631-7.

[26] Ferguson E, Williams L, O’Connor RC, Howard S, Hughes B, Johnston DW, Allan JL, O’Connor DB, Lewis CA, Grealy MA. \& O’Carroll RE. A taxometric analysis of Type D personality. Psychosom Med 2009;71:981-986.

[27] Watson D, Pennebaker JW. Health complaints, stress, and distress: Exploring the central role of Negative Affectivity. Psych Rev 1989;96:234-254. 
Table 1: Type D Personality as a Function of Mean (SD) ratings on each of the

\section{Illness Perceptions}

\begin{tabular}{llllc}
\hline Illness Perception & Type D & Non-Type D & F & p \\
Consequences & $8.03(0.9)$ & $6.07(1.11)$ & 50.64 & $\mathrm{p}<.001$ \\
Timeline & $7.92(1.17)$ & $6.43(1.45)$ & 50.97 & $\mathrm{p}<.001$ \\
Personal Control & $5.67(0.92)$ & $6.39(1.97)$ & 7.71 & $\mathrm{p}<.05$ \\
Treatment Control & $6.43(1.49)$ & $7.79(1.58)$ & 33.31 & $\mathrm{p}<.001$ \\
Identity & $6.6(1.15)$ & $4.89(1.88)$ & 45.42 & $\mathrm{p}<.001$ \\
Concern & $7.77(1.22)$ & $7.04(1.51)$ & 11.11 & $\mathrm{p}<.05$ \\
Emotions & $7.58(1.22)$ & $5.64(1.88)$ & 57.1 & $\mathrm{p}<.001$ \\
Comprehensibility & $6.72(0.65)$ & $7.35(1.21)$ & 15.21 & $\mathrm{p}<.001$ \\
\hline
\end{tabular}

